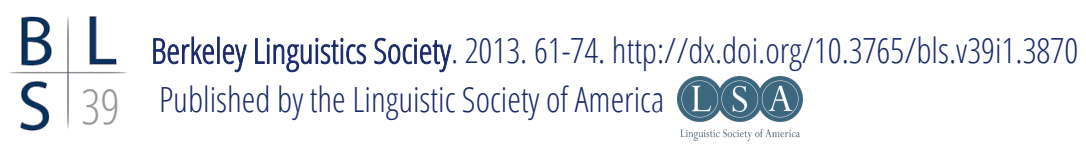

\title{
Do sighs matter? Interactional perspectives on sighing
}

\author{
ELLIOTT HOEY \\ University of California, Santa Barbara
}

Why do we sigh? The consensus on sighing as a physiological phenomenon regards it as important for restoring healthy variability to the respiratory system, specifically effecting lung compliance (Caro et al. 1960) and restoring the chemical properties of gas exchange (Cherniack et al. 1981). The psychological literature embarks from these accounts to link respiratory characteristics to psychological states, finding that sighs are produced in both positive (Keefe and Block 1982, Wuyts et al. 2011) and negative emotional states (Hirose 2000, Vlemincx et al. 2009). This research suggests that the physiological and psychological functions of sighing are intertwined since respiratory patterns are generally related to emotions (Boiten et al. 1994 [above references via Vlemincx et al. 2009]). By only focusing on the phenomenon as it occurs at the individual level, however, these studies ignore the social function that sighs may play. In treating them as acts performed in solitude, in other words, such studies assume sighs to be involuntary reflexes of private internal states. Cursory reflection would reveal, however, that the production of a sigh in conversation may be consequential for the interaction. Furthermore, in contrast to largely involuntary respiratory acts like yawning or sneezing, sighing is wholly manipulable, which suggests that its occurrence in interaction may be purposeful. In this preliminary report, I examine natural interactional data containing tokens of sighs to observe and describe the ways in which sighs may manifest as social action.

\section{$1 \quad$ Background}

One approximation of an interactional account of sighing comes from Teigen (2008), who administered two questionnaires on subjects' judgments of sighing 


\section{Elliott Hoey}

and conducted an experiment where actual sighs were observed. The first questionnaire revealed that subjects apprehend sighing in primarily negative emotional terms, though of moderately weak intensity. Subjects associated sighing with feelings of resignation, boredom, longing, exhaustion, and frustration (in that order). The second questionnaire found that the majority of subjects felt that most of their sighing was done alone and a-socially, and that such private sighs carried more intense feelings than ones produced when around others. An interesting contrast between one's own sighs and the sighs of others arose, namely, subjects attributed sadness to the sighs of others, but attributed a broader range of emotions to their own. In the experimental portion, subjects attempted two puzzles and their sighs were noted by experimenters. What emerged was the occurrence of sighing when receiving the puzzles, when handing them into the experimenters, and during the breaks after one or more unsuccessful attempts.

Teigen's study, while not an analysis of actual sighs 'in the wild', provides a helpful starting point for assessing popular attitudes towards sighs. His findings articulate how participants understand sighs, and suggest how sighs may be occasioned in interaction and how participants could design relevant responses. In delimiting the scope of emotions that conversationalists may display through a sigh, the present analysis can evaluate the accuracy of the experimental subjects' assessments of sighs. To do so, I take the view that emotion, whatever its psychophysiological manifestation, is in cases better described as a social phenomenon.

Rather than viewing emotions as an involuntary psychological force over which people have no control, they may be profitably understood as actions situated in social activities (Averill 1974, Goodwin and Goodwin 2000). In this view, displays of affect are orchestrated according to interactional contingencies and rendered visible through linguistic and bodily practices. This interactional approach to the study of emotions has revealed how nonlinguistic and paralinguistic phenomena may be communicative and intentional, rather than visceral eruptions. In this tradition, some researchers have approached emotion from the 'inside out', by presuming some psychological or cognitive state, then demonstrating its possible manifestations in interaction. Such studies have investigated the expression of frustration (Yu 2011), confusion (Drew 2005), disgust (Wiggins 2012), and surprise (Wilkinson and Kitzinger 2006). By contrast, other researchers have approached tokens of (non-)speech as they appear in conversation, and have explicated how they function within and organize conversation - an 'outside in' approach. Gail Jefferson, for instance, in a series of seminal papers, demonstrated how laughter in conversation is carefully systematized and coordinated by multiple parties to pursue multiple actions (Jefferson 1975, 1979, 1984). Similarly, other researchers have focused on the interactional usage of 'sound objects' like in-breaths (Lerner and Linton 2004), crying (Hepburn 2004, Hepburn and Potter 2007), clicks, and whistles (Reber 2012).

In the present study, I take the latter 'outside in' approach, surveying tokens 


\section{Do sighs matter? Interactional perspectives on sighing}

of sighs and analyzing their organization and discourse functions. In what follows, I describe the research methodology and data used for this examination, and then in what constitutes the bulk of the paper, I provide an analysis of sighs as they appear in interaction. Following this is a discussion of the findings, in which I make special note of the psychological and cognitive aspect of sighs. I close with a conclusion of the primary results of this study and remark on possibilities for further research.

\section{$2 \quad$ Methodology and data}

The data for this analysis come from the Santa Barbara Corpus of Spoken American English (Du Bois et al. 2000, Du Bois et al. 2003, Du Bois and Englebretson 2004, 2005), a corpus of audio recordings of natural, primarily conversational speech transcribed according to the conventions set out in Discourse Transcription (see Appendix) (Du Bois et al. 1993). In this corpus, sighs were identified by transcribers and labeled in the transcripts as $(S I G H)$. A search of the entire corpus returns 41 tokens of $(S I G H)$, of which seven representative samples are analyzed in this report. The methodological framework adopted is Conversation Analysis (cf. Atkinson and Heritage 1984, Sidnell and Stivers 2013), which recognizes interaction as the primordial site of sociality and seeks to explicate its organization through meticulous microanalysis of audiovisual recordings and their transcripts. Sighs are analyzed according to participants' orientations and understandings of their meaning and consequence in

a given situated environment.

\section{$3 \quad$ Analysis}

Two broad patterns emerge from the data. First, sighs may be produced for the display of affect, which may accomplish a variety of actions such as alignment or affiliation. And second, sighs may function in conversation on an interactional level, contributing to turn or topic management. Given the characteristic multifunctional nature of discursive elements, these two patterns may coexist in one token, so the conversational excerpts below were chosen as representative samples of their respective functions.

This study is predicated on the understanding that emotions appear in conversation as publicly available (i.e., visually and audibly perceptible) for copresent participants. A sigh is put 'out there' in order that others may perceive it and retroactively reconstitute its meaning in its contextualized environment. Often, this action takes the form of alignment/affiliation regarding some assessable item. In (1), four female friends are discussing Mister Samuel, a teacher they had in elementary school: 


\section{Elliott Hoey}

\section{(1) Fragment from SBC004 (Raging Bureaucracy)}

03 CAR: But he won't do anything to the girls if they give him backrubs.

04 SHA: ... That's right.

$05 \quad .$. That's righ $[\mathrm{t}]$.

06 CAR: [(TSK)]

07 SHA: ... (H) Mister $\sim$ Samuel .. had like,

$08 \quad$.. the [most] \&

09 CAR: [What a j]erk,

10 man.

11 SHA: \& ... unethical \&

12 CAR: (SIGH)

13 SHA: \& classroom,

14 [I can ever re]mem[2ber,

15 CAR: [He was a fool].

[2He was an absolute2] fool.

The extract begins with Carolyn's addition of a lecherous detail about the teacher as an example of his venality (line 3). Sharon affirms this detail, displaying her independent epistemic access to the matter in the process (lines 4-5), then proceeds to initiate a summary assessment (lines 7-8, 11, 13-14) (Drew and Holt 1998, Heritage and Raymond 2005). In overlap with Sharon, Carolyn appears to initiate a summary assessment of her own (lines 9-10), which is followed by a sigh (line 12), a re-evaluation, and an upgrade of that evaluation (lines 15-16).

Although the other participants do not respond to Carolyn's sigh directly, we can understand it as part of her assessment since it is situated between two other negative evaluations (jerk and fool/absolute fool). This sequence of ASSESSMENT + SIGH + SUMMARY ASSESSMENT demonstrates how Carolyn produces the sigh as an embodied continuation of her verbalized negative assessments. This token is representative in that the affect displayed is largely negative, a fact that is consistent with the psychological studies noted above. This same pattern may be seen in (2), where four girls converge on and share their assessments of strawberry daiquiris, which two of the girls had had at an earlier event.

(2) Fragment from SBC050 (Just Wanna Hang)

01 ARI: [Those strawberry daiquiris were so=] good.

02 NAN: [2Weren't they2] ^^so good?

03 ARI: [2(H)2]

04 DAN: .. What,

$05 \quad$.. you had strawberry daiquiris?

06 ARI: ... Yeah,

07 [with like] cream on the top.

08 NAN: [Mhm]. 
09 DAN: (GASP)

10 NAN: They were [so good].

11 KEL: [Yum].

12 DAN: ... (SIGH)[2=2]

13 ARI: [2They were so=2] $\operatorname{good}(\mathrm{H})$.

14

Can't you [3just --

15 NAN: [3They weren't like too3] strong,

Arianna gives an assessment of the drinks in first position (line 1), which is followed by a second assessment from Nancy (line 2). Dana responds to these evaluations with ritualized disbelief (Heritage, 1984:339), an action that typically makes relevant an expansion on the object of disbelief. Specifically, Dana displays disbelief through the open class repair initiator What (Drew, 1997) and by specifying the type of information she seeks (lines 4-5). Arianna in turn replies with a type-conforming affirmation (line 6) and an elaboration of the source of astonishment. ${ }^{1}$ These actions together prepare a place for the demonstration of surprise, delivered here in the form of a gasp (line 9), which is released as a sigh (line 12). This token is issued as part of a surprise sequence (Wilkinson and Kitzinger 2006), itself a component of the larger project of doing assessments together. After surprise is demonstrated, Dana produces a sigh to express longing or perhaps regret at having missed the opportunity to share in the experience.

The previous examples of affective sighs demonstrate how sighing may be used for the outward presentation of affect in evaluating some assessable. Notably, the sighs in (1) and (2) occur during talk as part of assessment sequences. By contrast, sighs also regularly appear outside of and on the borders of sequences, activities, and projects. That is, in addition to being indexically related to affect, sighs appear to invoke boundaries of discursive units, and, in doing so, are treated by participants as having interactional import. Consider first a non-interactional example to see how such a usage may have emerged. Here, Dana is involved in the mundane action of getting some juice for herself.

(3) Fragment from SBC050 (Just Wanna Hang)

01 DAN: ((opens juice bottle $))=($ SIGH $)$

$02 \quad$ ((pours juice, replaces cap on bottle $))$

$03 \quad(($ walks away, returns juice bottle $))$

$04 \quad((w a[l k s$ back $))$

$05 \quad[$ SIGH $)$

\footnotetext{
${ }^{1}$ Nancy, who had claimed equal access to the daiquiris, also provides the exact same response of a type-conforming affirmation ( $\mathrm{Mhm}$ in line 8 ) followed by an elaboration of the object of disbelief (They were so good in line 10).
} 


\section{Elliott Hoey}

This extract occurs outside of interaction; there is no talk, participation, or engagement to speak of. The two sighs are situated in an activity, but that activity is opening, pouring, and putting away the juice. Note how the sighs each appear after the recognizable completion of a sub-section of the project, namely, opening the bottle and returning from putting the bottle back. Where the sigh occurs is important because it ostensibly underlies the interactional function of sighs. The remainder of the examples in the analysis exhibits how sighs often appear at the boundaries of interactional episodes. This boundary-marking (or boundaryinvoking) function is particularly clear in the following exchange between loan officers who are voting on the passage of a loan:

\section{(4) Fragment from SBC014 (Bank Products)}

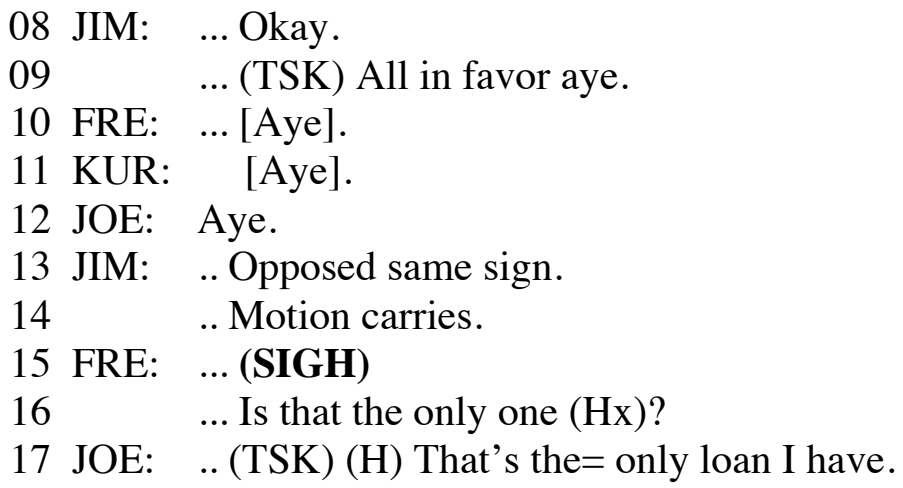

The fragment begins with Jim initiating a voting ritual known as viva voce ("live voice'), in which one party officially provides opportunities for affirmative votes (line 9), negative votes (line 13), and finalizes the result of those votes (line 14). Upon Jim's utterance of Motion carries, the activity is recognizably complete and there is no ratified next speaker (Sacks et al. 1974). In this transition space, Fred enters with a sigh (line 15), and then there is a beat of silence before he selfselects and initiates a new sequence (line 16). Much in the same way as the completion of a physical activity like opening a bottle prompts a sigh, this example shows how the completion of a communicative joint activity is a relevant place for a sigh. The brief pause after the sigh indicates that Fred did not intend to use the sigh as a place for starting a new sequence, but rather as a way to finalize the project and thereby publicly recognize that some new sequence or speaker transition would be relevant.

From this usage as a marker of the end of a project, conversationalists may extend sighs to other environments, suggesting a process of intersubjectification (Traugott 2010). The project-closing function seen in (4), by virtue of its syntagmatic position between projects, may be interpretable as opening a sequence. That is, because a sigh often appears at the recognizable termination of some sequence, it concurrently occupies both the ending of some episode and the 


\section{Do sighs matter? Interactional perspectives on sighing}

relevant beginning of some new one. ${ }^{2}$ This Janus-like function is observable in the following example involving the same women from (1), who are still discussing how terrible Mister Samuel was as a teacher.

\section{(5) Fragment from SBC004 (Raging Bureaucracy)}

01 SHA: [His classroom was like],

02 KAT: .. And [2that was the on2][3ly way to do it3].

03 CAR: [2No doubt2].

04 SHA: $\quad[3(\mathrm{H}) \mathrm{cra} 3] \mathrm{zy}$.

05 CAR: No doubt.

06

07

That man was insa=ne.

... [Definitely insa]ne.

10 that really frustrates me is that,

Their series of assessments of the teacher comes to a perceptible end by means of a summary assessment from Carolyn (lines 3, 5-7). This overlaps with Sharon's sigh (line 8) and the opening of a completely new sequence about a frustration of hers (lines 8-10). The sigh's position after a point of possible completion in Carolyn's turn (line 6) reveals how Sharon is oriented to the closure of the sequence about Mister Samuel. Moreover, Sharon's usage of a sigh to launch into a new sequence shows how the token has both retrospective and prospective qualities.

As a way to summarize, I close this section with a token that exhibits the uses detailed above, both affective and interactional. In this fragment, a group of friends are at home complaining about a neighbor and about neighborhood kids:

\section{(6) Fragment from SBC002 (Lambada)}

01 JAM: We're gonna have babies crying.

02

03 HAR: [(GROAN)]

$04 \quad .$. Well it's no worse than her screaming at em, 05 is it?

06 PET: ... Yeah but now you'll have both.

07 JAM: ... Yeah right.

$08 \quad$... Probably be like,

$09 \quad<$ VOX shut up you ki- VOX $>$,

10 you know,

\footnotetext{
${ }^{2}$ This place is also the structurally provided position for expanding the just-finished sequence, resuscitating a suspended or abandoned topic, or for the emergence of a lapse in talk.
} 


\section{Elliott Hoey}

\begin{tabular}{|c|c|}
\hline 11 & $\mathrm{XX} ?$ \\
\hline 12 & $\mathrm{Oh}=\mathrm{Go}=\mathrm{d}$ \\
\hline 13 & ... I feel -- \\
\hline 14 & I s- feel like such an old lady. \\
\hline 15 & But I -- \\
\hline 16 & they just really annoy me. \\
\hline 17 & (2.5) (SIGH) [kay], \\
\hline 18 MIL: & [Hunh]. \\
\hline $\begin{array}{l}19 \text { JAM: } \\
20\end{array}$ & $\begin{array}{l}\text { New subject, } \\
@ @\end{array}$ \\
\hline
\end{tabular}

In the course of a series of negative assessments, Jamie launches into an imagined reenactment of her own reaction (lines 8-9) to the babies crying (line 1) and the neighbor's screaming at em (line 4). The reenactment itself is a negative assessment, and comes to possible completion with you know? (line 10) and two inaudible syllables (line 11). However, her performance receives no audible uptake from Pete, James, or Harold, so Jamie expands with response cry $O h=$ $G o=d$ (line 12), which is a slightly more concrete expression of her frustration than the reenactment. This re-completion of her turn is again met with no turn transition, so she again expands with a direct articulation of her emotion (lines 1317). After $2.5 \mathrm{~s}$ of no uptake or transition (both of which would be relevant in this position), Jamie sighs, latching on kay (line 17) then proceeding to inaugurate a new sequence herself with New subject (line 19).

We may note several things about this sigh token. First, it can be justifiably understood as punctuating the just-articulated negative affect by Jamie, as it occurs directly after them in a place commonly reserved for just "post-completion stance markers' (Schegloff 1996). Second, since it occurs after a number of attempts by Jamie to implement turn-transition, the sigh may be seen as recompleting her turn, marking it as final, and furnishing another transitionrelevance place. In this way, Jamie does 'being finished', one consequence of which is turn transition. Miles responds to the sigh, however minimally, with $H u n h$, indicating his understanding that some response was relevant. Lastly, the token is treated as a relevant position for inaugurating a new topic, which can be seen in Jamie's latching kay onto the sigh then explicitly stating New subject (line 19). This token encapsulates and neatly summarizes the points made in this section, that sighs may be used affectively for implementing a variety of actions, and that they are often used for turn and topic management.

\section{$4 \quad$ Discussion and conclusion}

If the psychophysiological literature is to be taken at face value, sighs represent involuntarily generated by-products of a given internal emotional state, be it sadness, resignation, relief, or joy. Such a scenario suggests that people have 


\section{Do sighs matter? Interactional perspectives on sighing}

relatively little control over the production of a sigh, which is to say, little control over the expression of emotion. However, one observation that inspired this study was the fact that sighs are conscious and controllable. Indeed, as shown above, sighs do not appear randomly in conversation, but very often show up between interactional units, specifically at the boundaries of conversational projects, sequences, and turns. What this indicates is an alternative and complementary account to the psychophysiological accounts of sighing and its relationship to emotion.

As other researchers within the interactional tradition have demonstrated for other reaction tokens and response cries, the manipulability of a conventionalized sign is important for its public social value. Many tokens in the analysis exhibited an affective component, one that arose in the sequential position where such affect would be relevant. When such affect was tangential or immaterial to talk in progress, sighs were treated differently. These positions regularly coincide with the recognizable termination of a turn, sequence, activity or project, and in such places, a display of affect may or may not be relevant. The fact that sighs occupy such junctures shows participants' understandings of the respiratory tokens as relevant for marking or invoking boundaries. In this way, the production of a sigh does not always indicate a psychological state.

At the same time, this analysis does not wholly discount the previous physiological and psychological studies. Sighs are at times attended to in conversation and at other times treated as unaccountable, which would seem to complicate the division between what is socially meaningful versus what is internally valid. Such an observation means that sighs represent something intermediate between a purely interactional act and a purely physiological or psychological one. Indeed, synergistic research on cognition and emotions points away from a distinct division between the two domains, and submits that an combined approach should be taken in which they are integrated and analyzed as interdependent (Pessoa 2010, de Oliveira-Souza et al. 2011). One aspect of the present analysis that supports such a view is the multifunctionality of sighs.

In the process of grammaticalization, a given linguistic form is reanalyzed as performing some other function, and this function is then extended to other environments. That is, the cognitive processes of reanalysis and analogy undergird grammaticalization pathways insofar as speakers and hearers are constantly rearranging their linguistic representations along paradigmatic and syntagmatic axes. The current analysis suggests that something similar is at work in the multifunctionality of sighing. A sigh may be used in non-interactional contexts to signal the end of some physical activity, as in the successful opening, pouring, and returning of the juice. This usage may then be extended to a more abstract domain, as demonstrated by the sigh emphasizing the end of a viva voce ritual. Once a form is abstracted and reanalyzed, it may then be applied to other domains and develop different functions. The suggested syntagmatic reanalysis for sighs is this: in punctuating the end of some project, a sigh may also be 


\section{Elliott Hoey}

interpreted as initiating the following project. If this reanalysis is performed, then the sigh may be used solely to preface a new project or sequence.

While a strict definition of grammaticalization allows only movement from lexical forms to more grammatical ones, I understand the process as a more generalized cognitive one whereby concrete forms become more abstract. As such, a sigh can be a genuine candidate form to undergo grammaticalization. Moreover, evidence from sign languages converges on this same conclusion. Signers make use of non-linguistic elements as sources for grammaticalization, for instance, in the development of facial expressions into grammatical markers like polar questions, topic markers, conditionals (Macfarlane 1998, Janzen 1999), and in the development of gestures into classifier constructions (Zeshan 2003). That gestures are available for manipulation in such general cognitive processes indicates that paralinguistic and non-linguistic forms, as long as they play some role in the machinery and organization of conversation, should be taken into account for a complete picture of human interaction.

Indeed, given their lack of lexical or propositional content, it is easy to see how sighs may develop discourse-pragmatic functions. As Levinson has stressed (2006a, 2006b), a fundamental element of our capacity for conversation is intention reading, specifically our ability to model what someone else is thinking about our own intentions. This underlies the conversation analytic notion of recipient design, for utterances are tailored to be recognized and understood as embodying certain actions. In this sense, then, the inherent ambiguity of sighs permits a range of interpretations, including (but not limited to) the ones detailed in the examples above. That is to say, recipients are tasked with the responsibility of making sense of the multimodal signals in interaction, and the speaker must style an utterance in a way that is accessible, intelligible, and relevant. What the present analysis contributes to this discussion is the observation that even when a supposedly inner state is overtly expressed, these expressions may be treated as accountable or not. This means that participants in conversation make decisions about whether a sigh is intended to embody an internal psychological state, whether it is being used interactionally, some combination of the two, or neither. What remains to be shown, then, is whether the interactional functions of sighs are necessarily outgrowths of their psychophysiological reflexes. Their multifunctionality suggests a physiological origin with subsequent development of interactional functions. But, their very ability to change functions over time and across cases, and even their paradoxical interpretability as positive or negative, shows a plasticity of usage and potential to take on a life of their own, a life possibly divorced from any psychological or physiological grounding. This question merits further scrutiny, and sighs, given their variable accountability in interaction, represent a fruitful area of research.

Another natural outgrowth of this analysis would be to examine sighing in video recordings of conversation. Sighs have a characteristic gestural component in the heaving of the chest and shoulders. Sighs then are visually recognizable as such, and so even if the initial inhalation is undetectable in an audio recording, the 


\section{Do sighs matter? Interactional perspectives on sighing}

trajectory of a sigh may be clearly visible in video. This has implications for, e.g., the precision timing of actions, since participants may recognize a sigh early in its trajectory and may thereby tailor their actions or speech-in-progress to contingently respond to whatever action they interpret the sigh to be embodying.

In conclusion, sighs are not purely functions of an inner emotional state, but are also social in nature. Their expression is often indexical of a presumed emotional state, but the actual existence of that state is not necessarily consequential for interaction. Moreover, their appearance may be devoid of a supposed inner condition, functioning instead as boundaries for the closing or opening of conversational projects.

\section{Appendix: Discourse Transcription conventions}

$\begin{array}{llll}\cdot & \text { Final Intonation } & . . & \text { Short Pause (.2-.3) } \\ , & \text { Continuing Intonation } & (\mathrm{H}) & \text { Inhalation } \\ - & \text { Truncated Intonation } & (\mathrm{Hx}) & \text { Exhalation } \\ - & \text { Truncated Word } & \% & \text { Creaky Voice } \\ = & \text { Elongated Segment } & @ & \text { Laughter } \\ \wedge & \text { Word-level Contour Tone } & (()) & \text { Researcher's Comment } \\ {[]} & \text { Speech Overlap } & \text { X } & \text { Indecipherable Syllable } \\ I & \text { Syntactic Completion } & <\text { VOX> } & \text { Speech of Another } \\ \ldots .(. n) & \text { Long Pause }(.6 \text { or more }) & \text { <QUOT> Self Quotation } \\ \ldots & \text { Medium Pause (.3-.5) } & & \end{array}$

\section{References}

Atkinson, John M., and John Heritage, eds. 1984. Structures of social action: Studies in conversation analysis. Cambridge: Cambridge University Press. Averill, James R. 1974. An analysis of psychophysiological symbolism and its influence on theories of emotion. Journal for the Theory of Social Behavior 4:147-190.

Caro, C. G., J. Butler, and A. B. Dubois. 1960. Some effects of restriction of chest cage expansion on pulmonary function in man: An experimental study. Journal of Clinical Investigation 39:573-583.

Cherniack, N., C. von Euler, M. Glowgowska, and I. Homma. 1981. Characteristics and rate of occurrence of spontaneous and provoked augmented breaths. Acta Physiologica Scandinavica 111:349-360.

de Oliveira-Souza, Ricardo, Jorge Moll, and Jordan Grafman. Emotion and social cognition: Lessons from contemporary human neuroanatomy. Emotion Review 3:310-312.

Drew, Paul. 1997. 'Open class' repair initiators in response to sequential sources of troubles in conversation. Journal of Pragmatics 28:69-101.

Drew, Paul. 2005. Is confusion a state of mind? In H. te Molder and J. Potter, eds., Conversation and Cognition, 161-183, Cambridge: Cambridge University Press. 


\section{Elliott Hoey}

Drew, Paul and Elizabeth Holt. 1998. Figures of speech: Figurative expressions and the management of topic transition in conversation. Language in Society 27:495-522.

Du Bois, John W., Stephan Scheutze-Coburn, Danae Paolino, and Susanna Cumming. Outline of discourse transcription. 1993. In J. A. Edwards and M. D. Lampert, eds., Talking data: Transcription and coding in discourse research, 45-90, Hillsdale: Lawrence Erlbaum.

Du Bois, John W., Wallace Chafe, Charles Meyer, and Sandra A. Thompson. 2000. Santa Barbara corpus of spoken American English, Part 1. Philadelphia: Linguistic Data Consortium.

Du Bois, John W., Wallace Chafe, Charles Meyer, Sandra A. Thompson, and Nii Martey. 2003. Santa Barbara corpus of spoken American English, Part 2. Philadelphia: Linguistic Data Consortium.

Du Bois, John W. and Robert Englebretson. 2004. Santa Barbara corpus of spoken American English, Part 3. Philadelphia: Linguistic Data Consortium.

Du Bois, John W. and Robert Englebretson. 2005. Santa Barbara corpus of spoken American English, Part 4. Philadelphia: Linguistic Data Consortium.

Goffman, Erving. 1978. Response Cries. Language 54:787-815.

Goodwin, Marjorie H. and Charles Goodwin. 2000. Emotion within situated activity. In A. Duranti, ed., Linguistic Anthropology: A Reader, 239-257, Oxford: Blackwell.

Hepburn, Alexa. 2004. Crying: Notes on description, transcription, and interaction. Research on Language and Social Interaction 37(3):251-290.

Hepburn, Alexa and Jonathan Potter. 2007. Crying receipts: Time, empathy, and institutional practice. Research on Language and Social Interaction 40(1):89116.

Heritage, John. 1984. A change-of-state token and aspects of its sequential placement. In J. M. Atkinson and J. Heritage, eds., Structures of social action: Studies in conversation analysis, 299-345, Cambridge: Cambridge University Press.

Heritage, John and Geoffrey Raymond. 2005. The terms of agreement: Indexing epistemic authority and subordination in talk-in-interaction. Social Psychology Quarterly 68(1):15-38.

Hirose, S. 2000. Restlessness or respiration as a manifestation of akathisia: Five case reports of respiratory akathisia. Journal of Clinical Psychiatry 61:737-741.

Janzen, Terry. 1999. The grammaticization of topics in American Sign Languages. Studies in Language 23(2):381-316.

Jefferson, Gail. 1975. Notes on the sequential organization of laughter in conversation: Onset sensitivity in invitations to laugh. Unpublished manuscript.

Jefferson, Gail, 1979. A technique for inviting laughter and its subsequent acceptance declination. In G. Psathas, ed., Everyday Language - Studies in Ethnomethodology, 79-96, New York: Irvington Publishers.

Jefferson, Gail. 1984. On the organization of laughter in talk about troubles. In J. M. Atkinson and J. Heritage, eds., Structure of Social Action - Studies in 


\section{Do sighs matter? Interactional perspectives on sighing}

Conversation Analysis, 347-69, London: Cambridge University Press. Jefferson, Gail. 1985. An exercise in the transcription and analysis of laughter. In T. Van Dijk, ed., Handbook of Discourse Analysis, vol. III, 25-34, London: Academic Press.

Keefe, F. J. and A. R. Block. 1982. Development of an observation method for assessing pain behavior in chronic low back pain patients. Behavior Therapy 13:363-375.

Levinson, Stephen C. 2006a. The interaction engine. In N. J. Enfield and S. C. Levinson, eds., The Roots of Human Sociality: Culture, Cognition and Interaction: 39-69. Oxford: Berg.

Levinson, Stephen C. 2006b. Cognition at the heart of human interaction.

Discourse Studies 8(1):85-93.

Macfarlane, James. 1998. From affect to grammar: Ritualization of facial affect. Paper presented at the Sixth International Conference on Theoretical Issues in Sign Language Linguistics, Gallaudet University, Washington, DC.

Pessoa, Luiz. 2011. Emergent processes in cognitive-emotional interactions.

Dialogues in Clinical Neuroscience 12(4):433-48.

Pomerantz, Anna. 1984. Agreeing and disagreeing with assessment: Some features of preferred/dispreferred turn shapes. In J. M. Atkinson. and J. Heritage, eds., Structure of Social Action: Studies in Conversation Analysis, 57101, Cambridge: Cambridge University Press.

Reber, Elisabeth. 2012. Affectivity in interaction: Sound objects in English. Amsterdam: John Benjamins.

Sacks, Harvey, Emanuel Schegloff, and Gail Jefferson. 1974. A simplest systematics for the organization of turn-taking for conversation. Language 50:696-735.

Schegloff, Emanuel. 1996. Turn organization: One interaction of grammar and interaction. In E. Ochs, E. Schegloff, and S. A. Thompson, eds., Grammar and Interaction, 52-133, Cambridge: Cambridge University Press.

Schegloff, Emanuel. 2011. Word repeats as unit ends. Discourse Studies 13(3):367-80.

Sidnell, Jack and Tanya Stivers, eds. 2013. The Handbook of Conversation Analysis. Walden: Wiley-Blackwell.

Stivers, Tanya, Lorenza Mondada, and Jakob Steensig. 2011. Knowledge, morality and affiliation in interaction. In T. Stivers, L. Mondada, and J. Steensig (eds.) The Morality of Knowledge in Conversation, 3-24, Cambridge: Cambridge University Press.

Teigen, Karl Halvor. 2008. Is a sigh ‘just a sigh'? Sighs as emotional signals and responses to a difficult task. Scandinavian Journal of Psychology 49:49-57.

Traugott, Elizabeth Closs. 2010. Revisiting subjectification and intersubjectification. In K. Davidse, L. Vandelanotte, and H. Cuyckens, eds., Subjectification, Intersubjectification and Grammaticalization, 29-70, Berlin: De Gruyter Mouton.

Vlemincx, Elke, Ilse Van Diest, Steven De Peuter, Johan Bresseleers, Katleen 


\section{Elliott Hoey}

Bogaerts, Stien Fannes, Wan Li, and Omer Van Den Bergh. 2009. Why do you sigh? Sigh rate during induced stress and relief. Psychophysiology, 46:10051013.

Wiggins, Sally. The social life of 'eugh': Disgust as assessment in family mealtimes. British Journal of Social Psychology, 1-21.

Wuyts, Ruth, Elke Vlemincx, Katleen Bogaerts, Ilse Van Diest, and Omer Van den Bergh. 2011. Sigh rate and respiratory variability during normal breathing and the role of negative affectivity. International Journal of Psychophysiology, 82:175-179.

Yu, Changrong. 2011. The display of frustration in arguments: A multimodal analysis. Journal of Pragmatics, 43:2964-2981.

Zeshan, Ulrike. 2003. "Classificatory" constructions in Indo-Pakistani Sign Language: grammaticalization and lexicalization processes. In K. Emmorey, ed., Perspectives on classifier constructions in sign languages, 113-141, Mahwah, NJ: Erlbaum.

Elliott Hoey

University of California, Santa Barbara

Department of Linguistics

3421 South Hall

Santa Barbara, CA 93106-3100

elliotthoey@umail.ucsb.edu 